\title{
Effect of uniaxial load on microstructure and mechanical properties of Thixo-joint AISI D2 tool steel
}

\author{
F. Adnan, Z. Sajuri*, M. Z. Omar \\ Centre for Materials Engineering and Smart Manufacturing (MERCU), \\ Faculty of Engineering and Built Environment, Universiti Kebangsaan Malaysia, \\ 43600 Bangi, Selangor, Malaysia. \\ Phone: +603-8911 8017 \\ *Email: zsajuri@ukm.edu.my
}

\begin{abstract}
Tool steels are commonly used to cut metal materials due to their distinctive hardness, resistance to abrasion and deformation. However, tool steels are challenging to be joined using conventional fusion welding process. Recently, there are many studies in the semisolid joining process of metal materials by achieving the near-globular microstructure. Most studies of semisolid processes are hinged on attaining a globular microstructure when the metal alloy is in the semisolid state. However, very less information found on the effect of direct partial re-melting (DPRM) on the microstructural evolution and mechanical properties of the semisolid joined of tool steel. This study aims to analyse the effect of uniaxial force on the microstructural evolution and mechanical properties of the thixo-joint of D2 tool steel. A thixotropic property of metal was utilised to butt-join an AISI D2 tool steel by using the infrequent method of DPRM. A high frequency of induction heating is used to apply rapid heating during the joining process, and the effect of small compression load was investigated. The microstructural analysis showed that more desirable diffusion occurred between the grains of the thixo-joint sample with $2.5 \mathrm{~N}$ uniaxial load. The maximum strength of the thixojoint sample with load was higher than that of without load and the as-received samples. The average hardness value of the thixo-joint area increased to $400 \mathrm{HV}$ compared to the asreceived material due to the transformation of ferrite to the metastable austenite that filled by precipitated eutectic carbides at the grain boundaries.
\end{abstract}

Keywords: Thixo-joint; uniaxial load; microstructure; mechanical properties; AISI D2 tool steel.

\section{INTRODUCTION}

AISI D2 type steel is a particular group of ferrous alloys that encompass high-carbon and high-chromium cold-work tool steel of its grade. It has many attractive properties, such as high wear resistance, high compressive strength, and high hardness after hardening [1]. For this type of steel, conventional joining methods are not readily applicable since they are extremely prone to cracking when welded due to the high carbon content and high mechanical properties. The uneven expansion through localised melting and rapid cooling 
once the heat source removed will be caused the hardening of the heat affected zone and stresses that can lead to cracking. To overcome the problem of cracking of tool steel during welding, a relatively lower working temperature of thixo joining method is suggested by Omar et al. [2] and Mohammed et al. [3,4] to join the D2 tool steel. This method offers many advantages such as low forging force compared to conventional forging processes, the possibility of forming components with complicated and intricate shapes, reduction of steps in the forming process, less air entrapment and also less shrinkage porosity compared to conventionally casting processes. The advantages of the thixo-joining process over fusion welding and friction welding methods are the low working temperature and force applied [5].

Several studies on the relationship between the thixo-joining parameters and its microstructures and mechanical strengths have been reported. Liu et al. investigated the relationships between interfacial shear strength and solid fraction of aluminium alloy, bonding pressure and time of stainless steel and semisolid aluminium alloy using semisolid joining clad method [6]. The finding shows that the best solid-liquid fraction for semisolid joining was at $30 \%$ solid fraction of aluminium alloy. This study also highlighted that by increasing the bonding pressure and pressure time, the interfacial shear strength increases rapidly.

The effects of joining temperature, holding time and post-weld heat treatment on microstructural features and mechanical properties of AISI D2 thixo-joining was reported by Mohamad et al. [7]. The study showed that temperature is the most critical joining parameter to increase the joinability of the interface. A defect-free thixo-weld-joint of AISI D2 tool steel can be successfully produced with a thixo-joining temperature of $1300^{\circ} \mathrm{C}$. However, at a thixo-joining temperature lower than $1300^{\circ} \mathrm{C}$, a series of cracks was observed across the entire joint surface due to the existence of voids and gaps. Other study conducted by Mohammed et al. showed that thixo-joining method could avoid the formation of dendritic microstructure at the joint zone of AISI D2 tool steel and 304 stainless steel and results in a high bonding quality [8].

A study of microstructure and mechanical properties of M2 and D2 tool steels thixo-joining has been reported by Kalaki et al. [9]. From the study, the microstructure and mechanical properties of the thixo-joint showed evidence of a good quality of joining. It is reported that the grain boundaries at the joint region are weaker than the interior grains due to the presence of voids and carbide networks along the grain boundaries which are believed to be the reduction factors of the joint strength. In another study, Kalaki et al. suggested that compression stress of $1 \mathrm{MPa}$ may decrease the content of voids and strengthen the boundaries would improve the strength of the joint [10].

Therefore, in this study, it is essential to identify the effect of a constant small compression load during the joining process on the microstructure evolution and mechanical properties of thixo-joined AISI D2 tool steels. A high-frequency induction heater was used to heat up and join AISI D2 tool steels using a direct partial re-melting method. The effect of a compression load on the microstructure, hardness distribution along the joint area and tensile properties of the D2 to D2 thixo-joint is discussed. 


\section{METHODS AND MATERIALS}

\section{Materials}

An AISI D2 cold-work tool steel was used in this study. The material was supplied by ASSAB Industries Sdn. Bhd., Malaysia. The as-received material has gone through a soft annealing process, i.e. heating to $850^{\circ} \mathrm{C}$, followed by cooling at $10^{\circ} \mathrm{C} / \mathrm{h}$ to $650^{\circ} \mathrm{C}$ and finally air cooled. The chemical composition of the as-received material was determined by arch spark technique is shown in Table 1.

Table 1. The chemical composition of AISI D2 tool steel (wt. \%).

\begin{tabular}{cccccccccc}
\hline $\mathrm{C}$ & $\mathrm{Si}$ & $\mathrm{Mn}$ & $\mathrm{P}$ & $\mathrm{Cr}$ & $\mathrm{Mo}$ & $\mathrm{Ni}$ & $\mathrm{Cu}$ & $\mathrm{V}$ & $\mathrm{Fe}$ \\
\hline 1.6 & 0.254 & 0.254 & 0.022 & 10.8 & 0.826 & 0.069 & 0.059 & 0.826 & Bal. \\
\hline
\end{tabular}

\section{JmatPro Simulation}

In this work, JmatPro software was used to estimate the liquid fraction as well as the solid and liquid temperature of the investigated materials. Phase equilibrium diagram of the AISI D2 tool steel simulation result is illustrated in Figure 1. From this equilibrium diagram, it is noticed the phase transformations of carbides $\left(\mathrm{MC}, \mathrm{M}_{23} \mathrm{C}_{6}\right.$, and $\left.\mathrm{M}_{7} \mathrm{C}_{3}\right)$, austenite, ferrite, and liquid occurred within the temperature range of $500^{\circ} \mathrm{C}$ to $1600^{\circ} \mathrm{C}$. It also shows that the solidus and liquidus temperature occurred at around $1200^{\circ} \mathrm{C}$ and $1400^{\circ} \mathrm{C}$, respectively. The austenite phase appears approximately at $790^{\circ} \mathrm{C}$ and melts completely at $1400^{\circ} \mathrm{C}$. A small volume (around $1-2 \%$ ) of MC carbide completely dissolve at a temperature of $750^{\circ} \mathrm{C}$ after reheating while the $\mathrm{M}_{7} \mathrm{C}_{3}$ carbide completely dissolves at $1251^{\circ} \mathrm{C}$. Based on this diagram, the $\mathrm{M}_{7} \mathrm{C}_{3}$ carbides is lie at the beginning of the semisolid region.

Meanwhile, the entire $\mathrm{M}_{23} \mathrm{C}_{6}$ carbides dissolve at around $889^{\circ} \mathrm{C}$. However, the presence of $\mathrm{M}_{23} \mathrm{C}_{6}$ carbides is relatively small at around $5 \%$. The $\mathrm{D} 2$ tool steel starts melting at $1200^{\circ} \mathrm{C}$, and a full molten metal phase is achieved at $1400^{\circ} \mathrm{C}$ as shown in Figure 2 . The range of the starting and complete melting temperatures were then selected as the temperature windows for this study. Based on the previous studies, the usual working range for a thixoforming process is between $20-50 \%$ liquid percentage [2, 3]. Figure 2 shows the liquid fraction of D2 tool steel as a function of temperature. In this study, the liquid fraction selected to be used for the thixo-joining process was about 34-35\%. Therefore, the heating temperature to obtain this liquid fraction was determined at $1300^{\circ} \mathrm{C}$ as shown in Figure 2. 


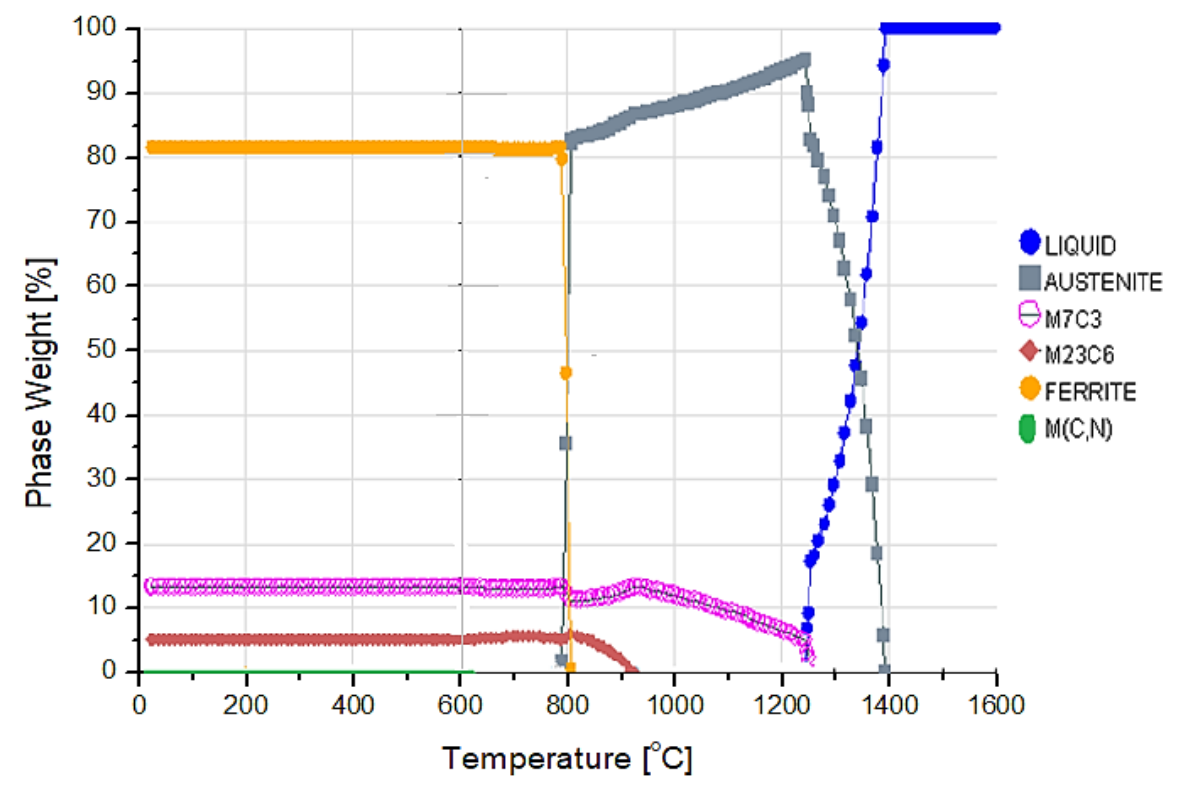

Figure 1. Phase equilibrium diagram of AISI D2 tool steel obtained from JMatPro simulation.

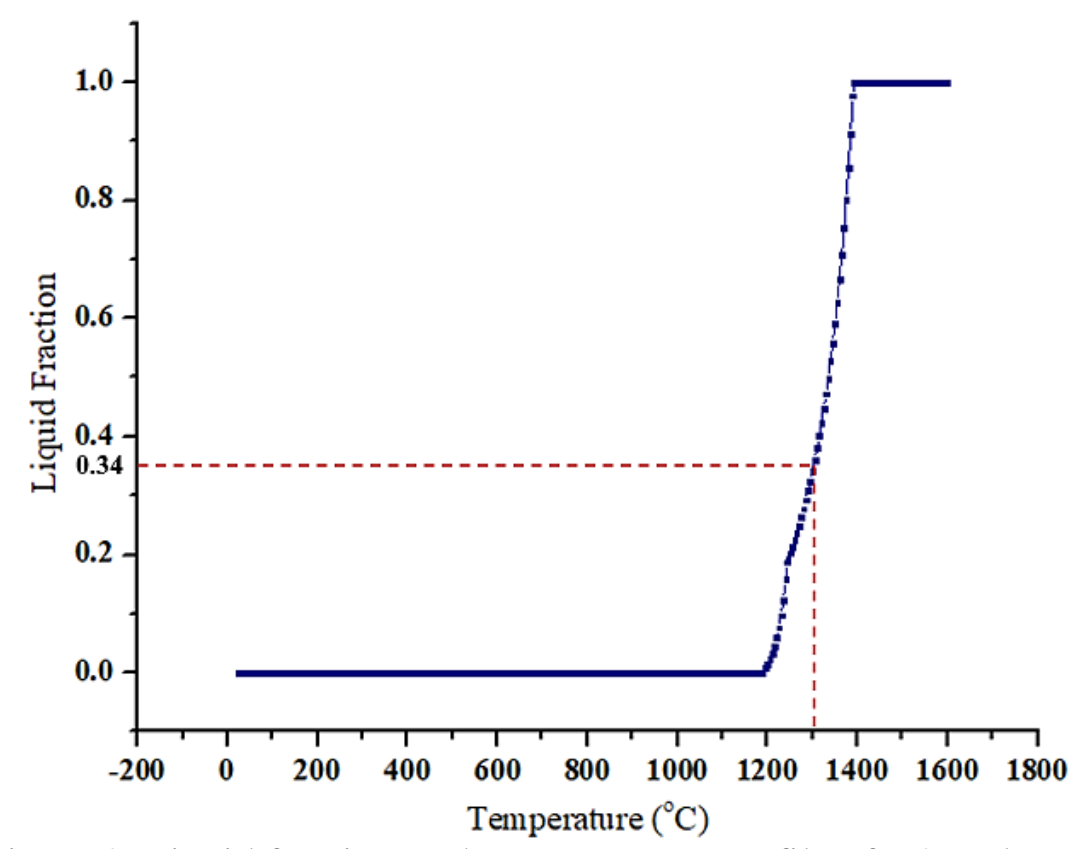

Figure 2. Liquid fraction to the temperature profile of D2 tool steel.

\section{Direct Partial re-melting Experiment using Induction Heating}

The direct partial re-melting experiment was performed using a high-frequency induction heating machine with a capacity of $50-80 \mathrm{~kW}$. The joining process was conducted at EFD Induction Sdn. Bhd. Shah Alam. Before the joining, the materials were cut flat into samples size of $10 \mathrm{~mm} \times 10 \mathrm{~mm} \times 80 \mathrm{~mm}$, respectively using an EDM wirecut. The surface area of the joining was cleaned using acetone to make sure the surface is free from any dust or dirt. Figure 3 and 4 show the schematic diagram of the experimental setting and the samples 
holding for the thixo-joining. Jigs were used to hold both top and the bottom samples of D2 tool steel. A load was applied onto the top sample during the thixo-joining process as per Figure 4. A pyrometer is used to detect the joining surface temperature. By using the induction heating machine, it takes 30 seconds to reach the joining temperature of $1300^{\circ} \mathrm{C}$. After the desired temperature is reached and the joining process takes place, the heating was removed, and the sample was then cooled in air at the room temperature. Table 2 summarised the process parameter for this process.

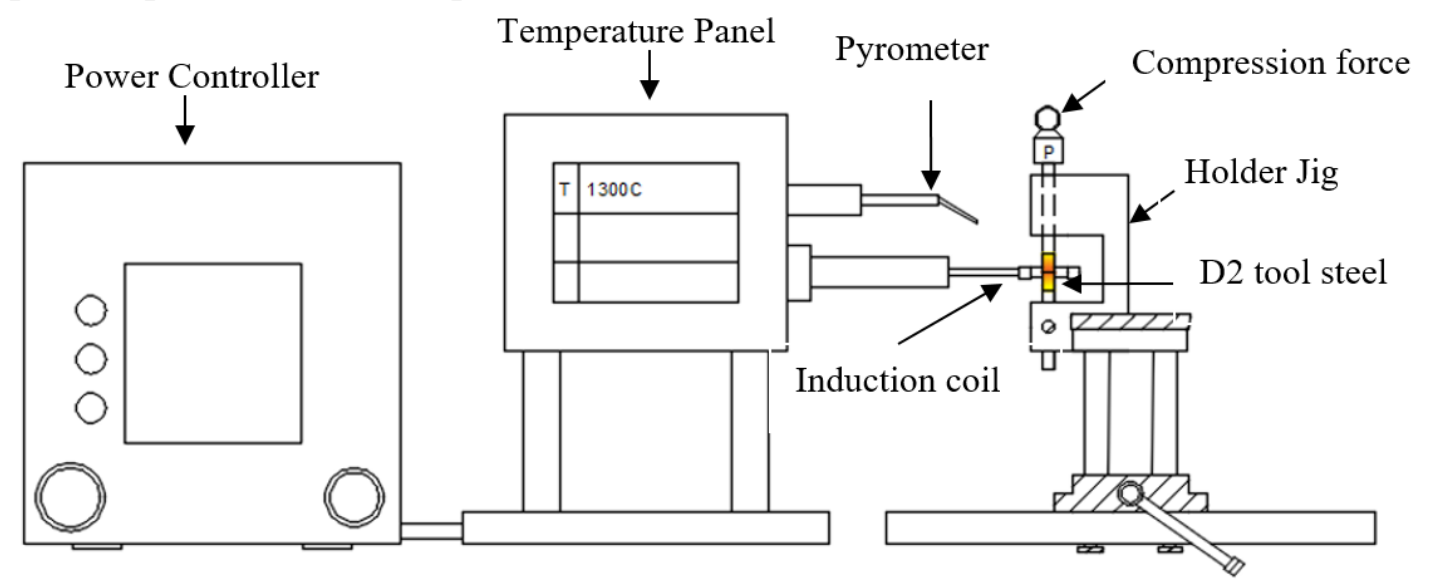

Figure 3. Schematic diagram of the experimental setting
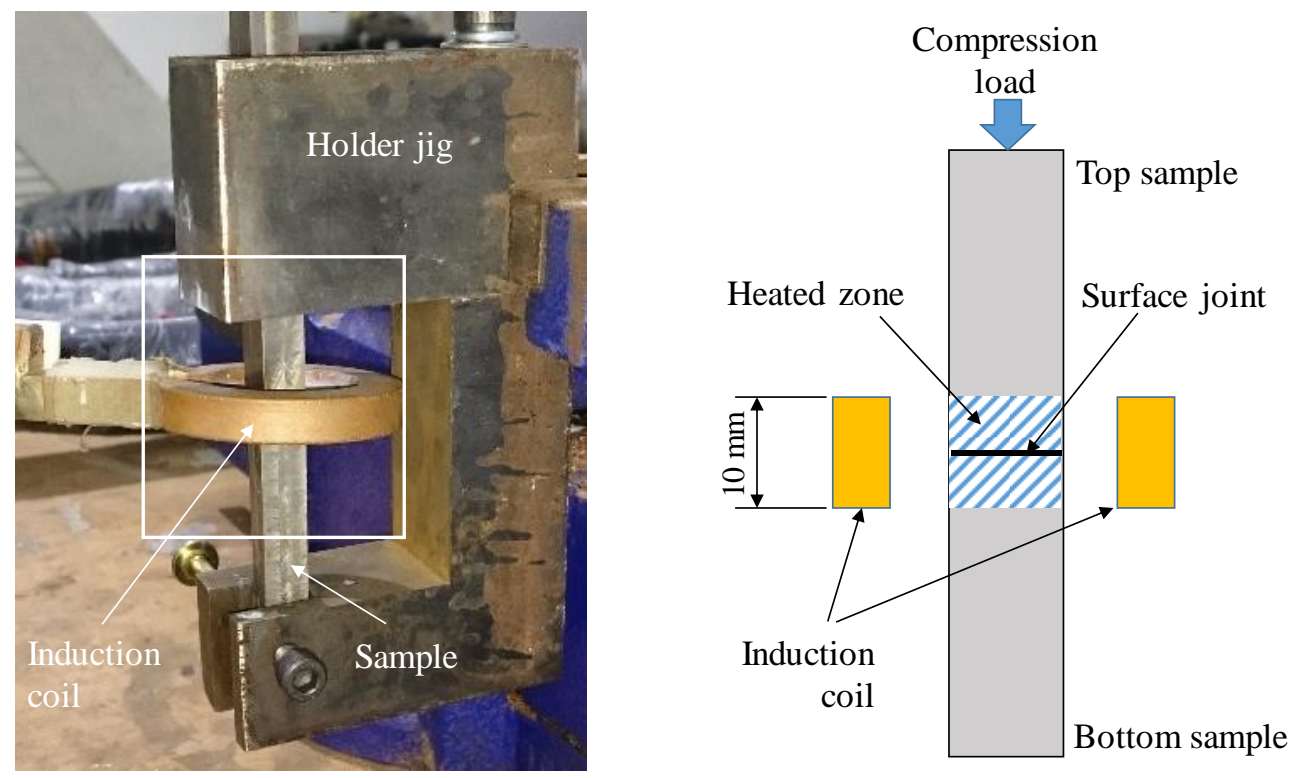

Figure 4. Configuration of the test setup (left) and the schematic diagram of the heated zone (right) during the thixo-joining process. 
Table 2. Process parameters for thixo-joining using induction heating.

\begin{tabular}{lc}
\hline Parameter & Value \\
\hline Power $(\mathrm{kW})$ & 17 \\
Frequency $(\mathrm{Hz})$ & $50 / 60$ \\
Voltage $(\mathrm{V})$ & $400-480$ \\
Temperature $\left({ }^{\circ} \mathrm{C}\right)$ & 1300 \\
Duration $(\mathrm{s})$ & 30 \\
Load $(\mathrm{N})$ & 0 and 2.5 \\
\hline
\end{tabular}

\section{Microstructural Analysis}

After the joining, samples were sectioned into $20 \mathrm{~mm} \times 10 \mathrm{~mm} \times 3 \mathrm{~mm}$ using an electrical discharge machining (EDM) wire cut for the metallographic analysis. The cut samples were hot mounted in a Bakelite before grind using \#400 - \#1200 grit silicon carbide papers. The samples were then polished by using LECO polishing cloth with $1 \mu \mathrm{m}$ diamond paste to get a mirror-like surface before etching. Vilella's reagent $(1 \mathrm{~g}$ picric acid, $5 \mathrm{~mL}$ hydrochloric acid, and $95 \mathrm{~mL}$ ethyl alcohol) was used as the etching solution. The surface of the sample was immersed in the etchant for 5 to 10 seconds to reveal the microstructure followed by rinsing with the distilled water and then dried in the air. Microstructural examination of prepared samples was done using optical microscopy (BX-51 Olympus).

\section{Hardness Test}

Samples for the hardness test were prepared similarly to the samples for microstructural analysis but without the etching process. Three types of samples were prepared, i.e. the asreceived material, the thixo-joined sample with $2.5 \mathrm{~N}$ load, and thixo-joined sample without load. The Vickers hardness test was performed according to the ASTM E384 hardness testing standard. A load of $1 \mathrm{~kg}$ force was applied for a dwell time of $15 \mathrm{~s}$. The Vickers hardness was measured along the $20 \mathrm{~mm}$ across the joining area. The hardness indentation was made in $1 \mathrm{~mm}$ interval.

\section{Tensile Test}

Figure 5 shows the tensile test sample cut using an EDM wire cut machine after the thixojoined. The specimen was prepared according to the ASTM E8 standard with a gauge length of $30 \mathrm{~mm}$. A $100 \mathrm{kN}$ capacity Zwick Roell universal testing machine (UTM) was used to perform the tensile test. A long-stroke extensometer was used to measure the total elongation values from the beginning of the test until specimen fracture. A constant test speed of $1.8 \mathrm{~mm} / \mathrm{min}$ was applied throughout the test. Three types of samples were tested, i.e. the asreceived, the thixo-joint sample without load, the thixo-joint sample with $2.5 \mathrm{~N}$ load. The tensile test was done at room temperature.

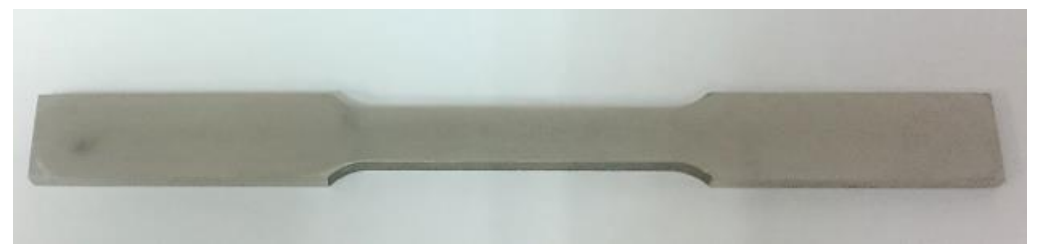

Figure 5. Flat specimen used for tensile testing. 


\section{X-Ray Diffraction (XRD)}

$\mathrm{X}$-ray diffraction (XRD) analyses were carried out by using an X-ray diffractometer (Bruker D8 Discover) using $\mathrm{Cu} \mathrm{K \alpha}$ radiation with a scan rate of $5^{\circ} / \mathrm{min}$ and angular $2 \theta$ range from $0^{\circ}$ to $90^{\circ}$. X-Ray Diffraction was done to analyse the presence of elements and phases in the steel specimen before and after the thixo-joining.

\section{Heating Profile}

Figure 6 shows the heating profile of the specimen at $17 \mathrm{~kW}$. At the first $10 \mathrm{~s}$, the heating profile shows a rapid increment of temperature at a heating rate of $110^{\circ} \mathrm{C} / \mathrm{s}$. From $10 \mathrm{~s}$ to 15 $\mathrm{s}$, the heating rate decreased to about $50^{\circ} \mathrm{C} / \mathrm{s}$. The heating rate further decreased from $15 \mathrm{~s}$ until $35 \mathrm{~s}$. This heating profile shows that a high energy/heat is transferred during solid-solid transformation, while a low heat/energy applied when the solid-liquid transformation.

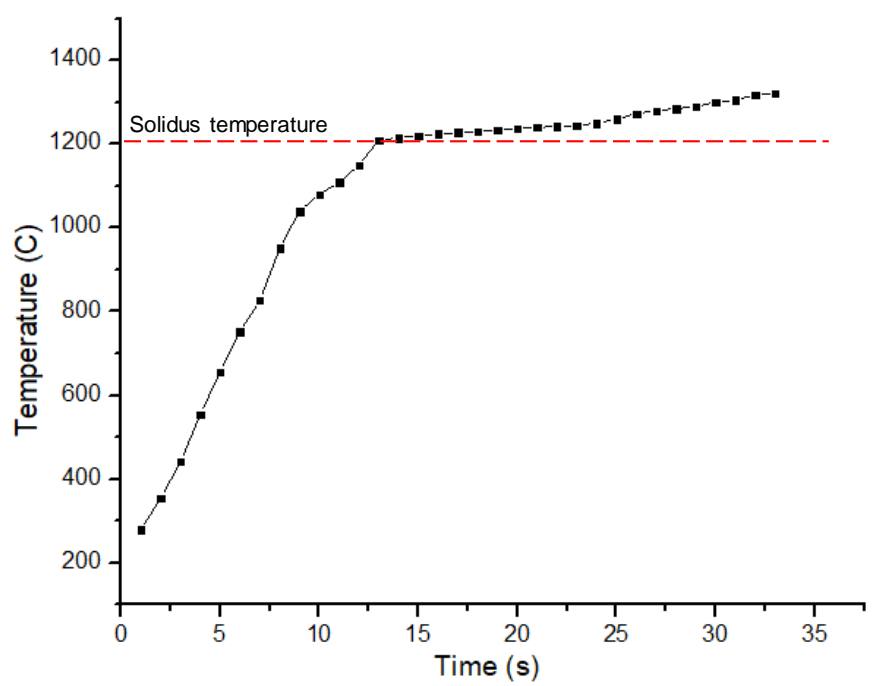

Figure 6. Heating profile at the heating capacity of $17 \mathrm{~kW}$. 


\section{RESULTS AND DISCUSSION}

Figure 7 shows the microstructure of the as-received material of annealed AISI D2 tool steel which consists of coarse carbides at the grain boundary with finer carbides distributed homogeneously in the ferrite matrix. A similar microstructure of an annealed cold-work tool steel was reported by Liu et al. [11] and thus confirmed that soft annealing treatment had been carried out on the as-received material as described by the supplier.

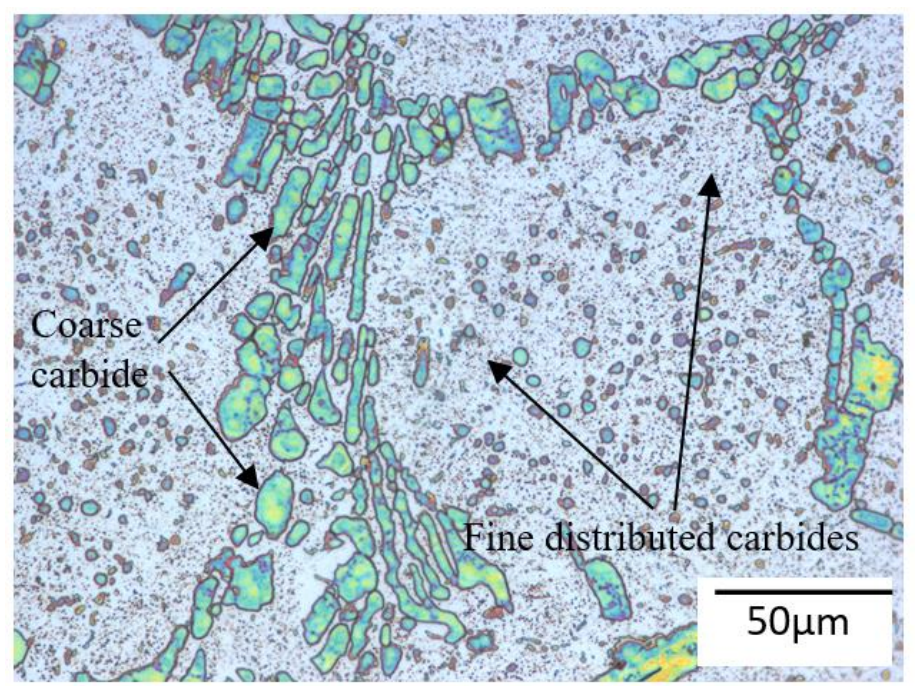

Figure 7. The microstructure of the as-received materials.

Figure 8 (a) and (b) showed the joined samples without load and with $2.5 \mathrm{~N}$ compression load, respectively. From the figure, it clearly shows that the joined sample without load has a relatively un-deformed shape at the joining compared to the sample with $2.5 \mathrm{~N}$ loading. For the loaded sample, a $2.5 \mathrm{~N}$ load was continuously applied onto the top of the sample during the thixo-joining process and the joined sample swollen at the joining area. These phenomena happen because the force from the top push to the semisolid materials of the heated zone to squeeze out.
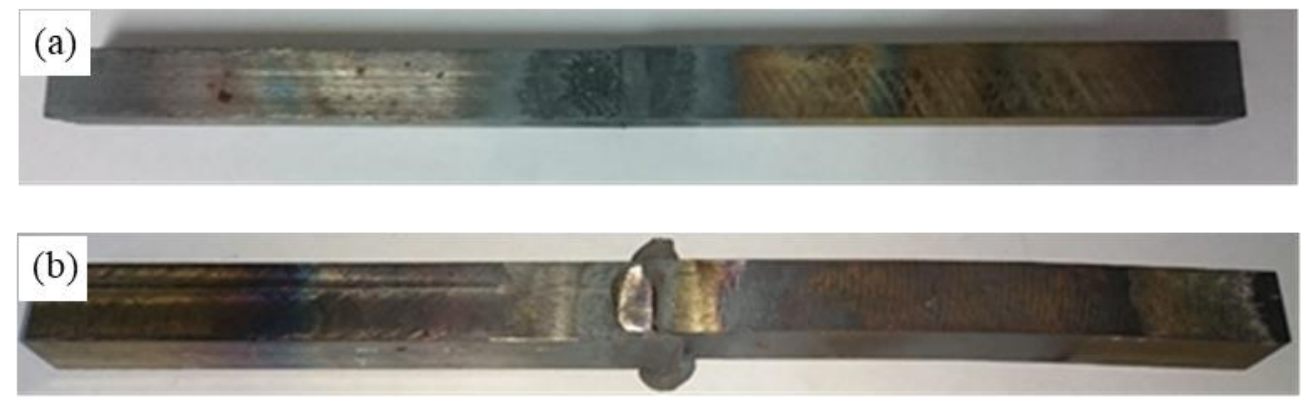

Figure 8. The thixo-joined samples (a) Without load and (b) with a $2.5 \mathrm{~N}$ load. 
Figure 9 presents the microstructures of two thixo-joined specimens with and without load after joining at $1300^{\circ} \mathrm{C}$. From these microstructures, it can be seen clearly that the joining interface line disappeared for both joining conditions where the grains at the interface diffused in each other. However, a distinct difference identified from these microstructures was the volume of eutectic carbides at the grain boundaries of austenite was more significant for the specimen without load compared to that of with $2.5 \mathrm{~N}$ load. The eutectic carbides forms during the cooling from $1300^{\circ} \mathrm{C}$ and results in the transformation of the remaining liquid into eutectic, $\left(\mathrm{L}-\gamma+\mathrm{M}_{7} \mathrm{C}_{3}\right)$. During the thixo-joining, the applied load of $2.5 \mathrm{~N}$ squeezed the liquid from interparticle gaps. As the liquid is squeezed out, the local volume fraction liquid to solid changes and the viscosity of the mixture also varies. As the maximum of viscosity achieved, the mixture behaves effectively like a solid. Particles at the interface of the top and bottom specimens which remains attached for sufficiently long periods can be joined together due to the thermal diffusion. This event can be noticed distinctly from Figure 10 where diffusion of the grains boundaries occurred more prominent due to the load applied during the thixotropic condition of the joint. The diffusion of grains and less amount of eutectic carbides at the grain boundaries could help for better mechanical properties of the thixo-joint.

In contrast, the liquid phase was not squeezed out from the interparticle gaps in the thixo-joint without load. The volume fraction, viscosity and microstructure of the mixture will remain. Therefore, the amount of undissolved eutectic carbides at the interparticle gaps is more than that in the specimen with the load. This finding is supported by a report written by Burgos et al. [12] who mentioned that applying force during the thixo-joining of metals will alter the microstructure permanently due to the changes of volume fraction and viscosity of the mixture.

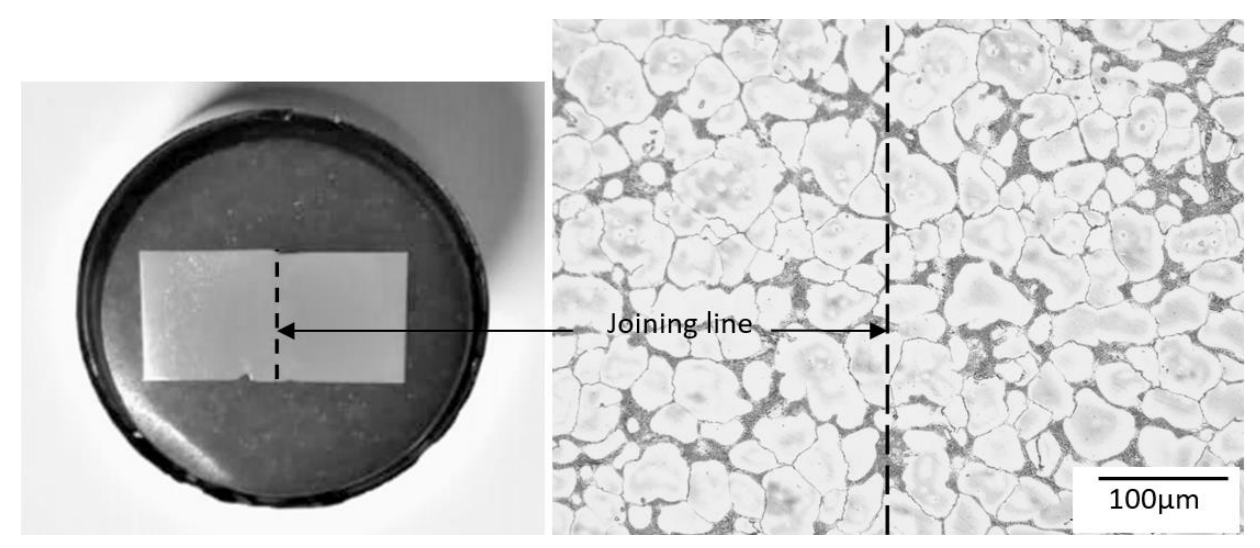

(a) 


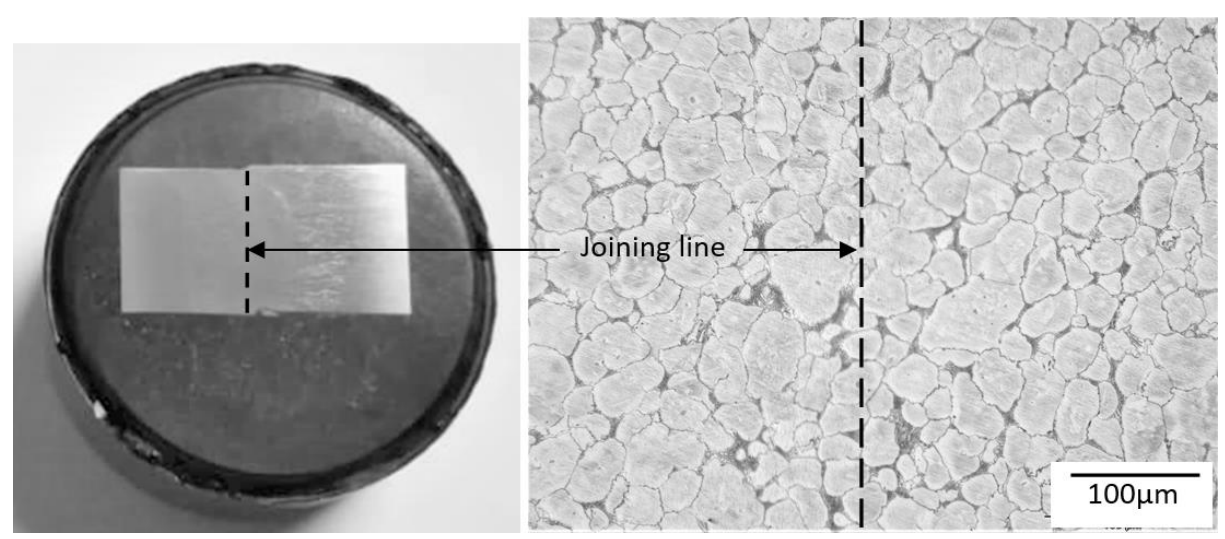

(b)

Figure 9. Optical microstructure of the thixo-joint samples, (a) without load (b) with a 2.5 $\mathrm{N}$ load.
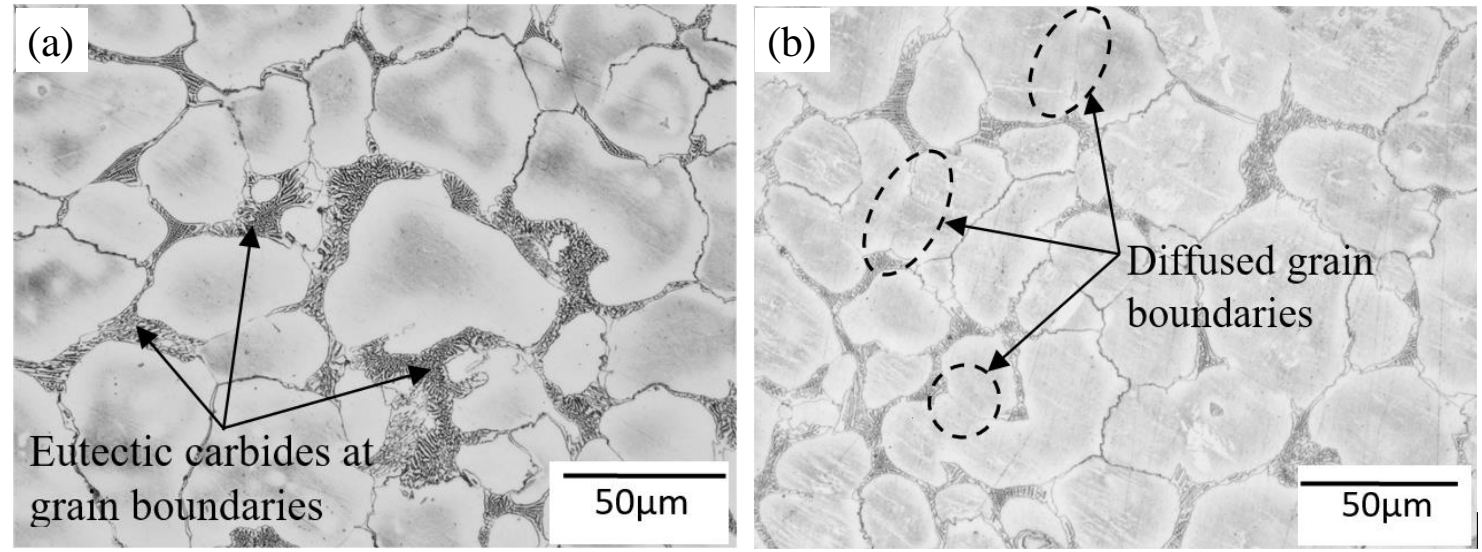

Figure 10. Higher magnification of thixo-joining area. (a) Eutectic carbides at the interparticle gaps in the sample without load, and (b) diffusion of grains boundaries in the sample with $2.5 \mathrm{~N}$ load.

Tensile properties of the thixo-joint specimens were derived from stress-strain curves obtained from the tensile tests as shown in Figure 11. The stress-strain curve for the asreceived AISI D2 tool steel is also included for comparison. From the results, the maximum strength of $652 \mathrm{MPa}$ was obtained from the thixo-joint sample with $2.5 \mathrm{~N}$ load. While for the thixo-joint sample without load, the maximum strength was significantly low at $414 \mathrm{MPa}$. The maximum strength of the loaded sample is on a par with that of the as-received material. These values notify that the load applied during the thixo-joining process improves the mechanical strength of the joint. This result is in agreement with the microstructural evolutions observed where grains diffusion and less amount of eutectic carbides at the interparticle gaps found in the $2.5 \mathrm{~N}$ loaded sample compare to that of without load. This finding is similar to a result reported by Roberts et al. which stated that the increase of compression load might decrease the content of voids and further strengthen the boundaries [13]. The statement is also supported by Alvani et al. [14] and Liu et al. [11] where they reported the increase in strength of the joint is associated with the applied pressure that promotes diffusion of the liquid phase and plastic deformation of the solid grains. Increasing 
pressure will increase the strength of the joint. Kalaki et al. reported that by applying pressure during the thixo-joining, the void reduced, and consequently, the strength of the joint increased. The voids of a liquid fraction are due to the slow cooling that cultivates void in the semisolid condition [9].

The fracture strain of both thixo-joined samples with and without load was lower compared to that of the as-received sample. The fracture strain of the thixo-joined samples with and without load was $0.7 \%$ and $0.3 \%$, respectively. This was due to the undissolved carbides networks along the grain boundaries of the thixo-joined samples contributes to the decreasing of ductility. In the as-received sample, fine carbides are distributed homogeneously in the grains, as shown in Figure 7, contributed to the higher ductility of $4.5 \%$ strain. A similar result was reported by Muro et al. [15] where the presence of primary carbides is believed to decrease the toughness of the D2 tool steel.

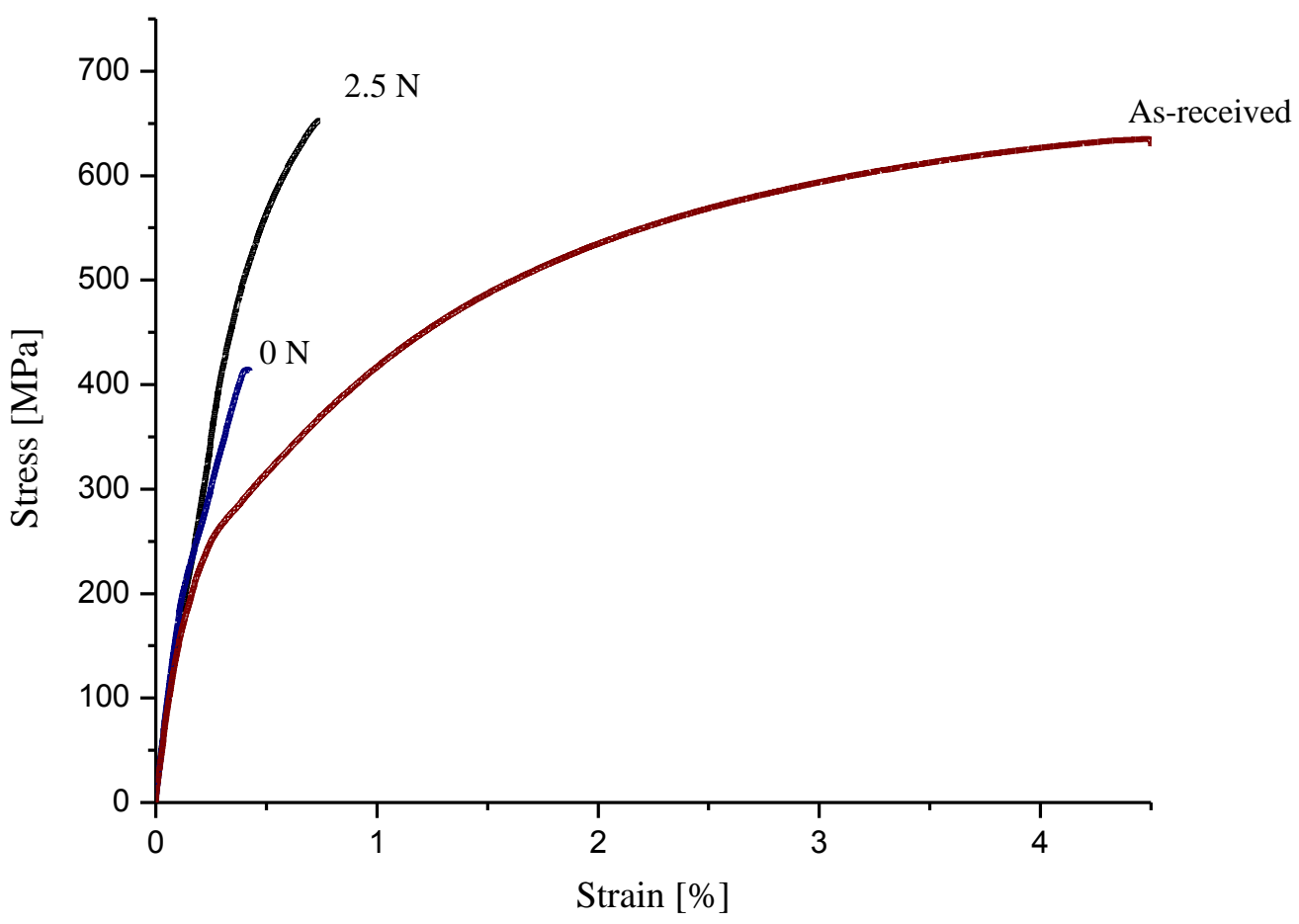

Figure 11. Tensile properties of the thixo-joined and as-received samples

The hardness profile of thixo-joined samples with and without load is plotted in Figure 12. As a reference, the average hardness of the as-received material is $226 \mathrm{HV}$. From the figure, the overall hardness of the thixo-joining area for the sample without load and with $2.5 \mathrm{~N}$ load was higher compared to that of the as-received base material which is only around $226 \mathrm{HV}$. The average hardness value within $5 \mathrm{~mm}$ distance from the joint line for the thixojoined samples with $2.5 \mathrm{~N}$ load and without load was around $400 \mathrm{HV}$. The increase in hardness of the thixo-joint samples was due to the phase change of ferrite to the metastable austenite while precipitated eutectic carbides fill the remaining interparticle gaps at the grain boundaries. Mohammed et al. [8] reported a similar finding, where the increasing hardness of thixo-joint was due to the transformation of the austenite phase with precipitated eutectic carbides at the grain boundaries. 
At a distance of 5 to $10 \mathrm{~mm}$ from the joint line, the hardness value increased up to $850-890 \mathrm{HV}$. The significant increment in hardness of this area was due to the change in the microstructure of heat affected zone (HAZ) as shown in Figure 13. The microstructure of the HAZ revealed that most of the finely distributed carbides dissolved into the matrix to form a stable solid solution of austenite (bright in colour) while the coarse carbides network at the grain boundaries forms larger carbides (dark in colour) remain at the boundaries which attributed to the increasing in hardness. It is noted that the size of the heated area of the sample is equivalent to the size of the induction coil which is $10 \mathrm{~mm}$ in thickness as shown in Figure 4. Therefore, the area beyond $5 \mathrm{~mm}$ distance from the joint line is the heat affected zone. The peak hardness was measured at a distance of about $10 \mathrm{~mm}$ from the joint line. Beyond this distance, the hardness value gradually decreases until reaching the hardness of the based metal at around $17 \mathrm{~mm}$ from the joint line. According to Burgos et al. [12], HAZ is created by a short but very intense action of the thermal energy in which it will increase the hardness and brittleness of materials.

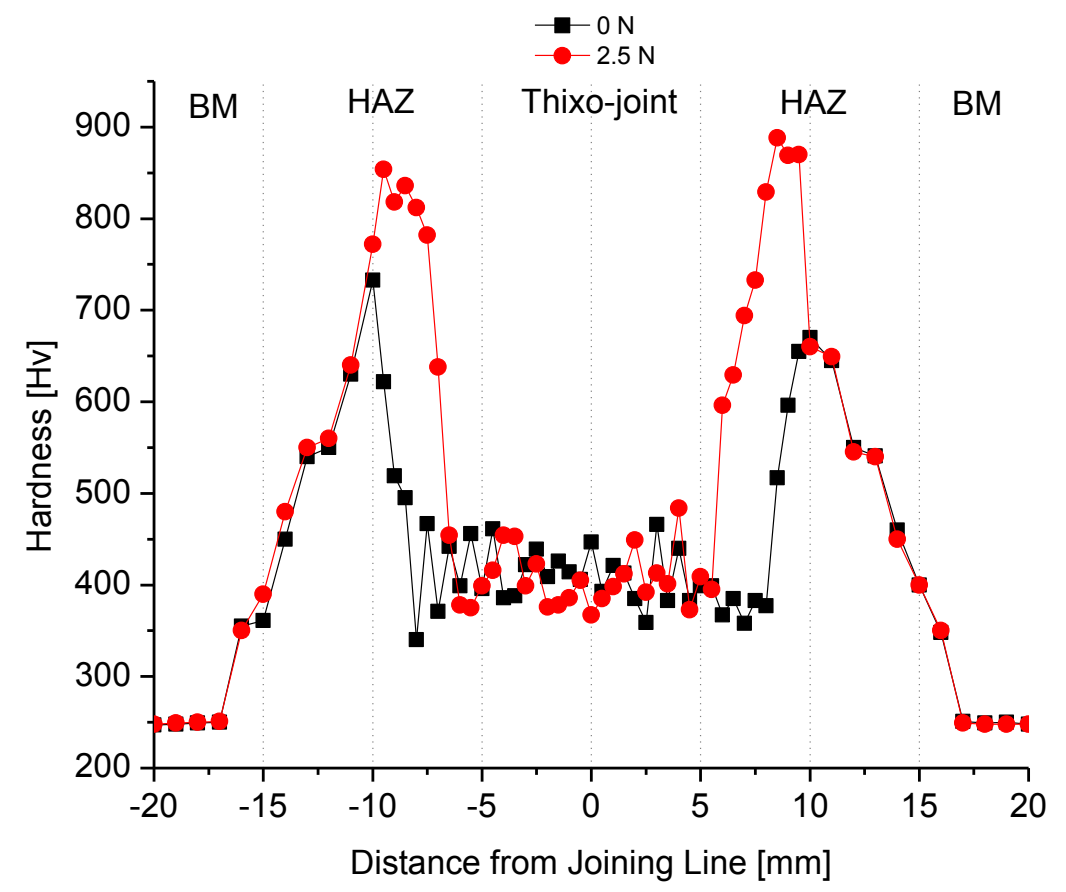

Figure 12. Hardness distribution for $0 \mathrm{~N}$ and $2.5 \mathrm{~N}$ of thixo-joint samples. 


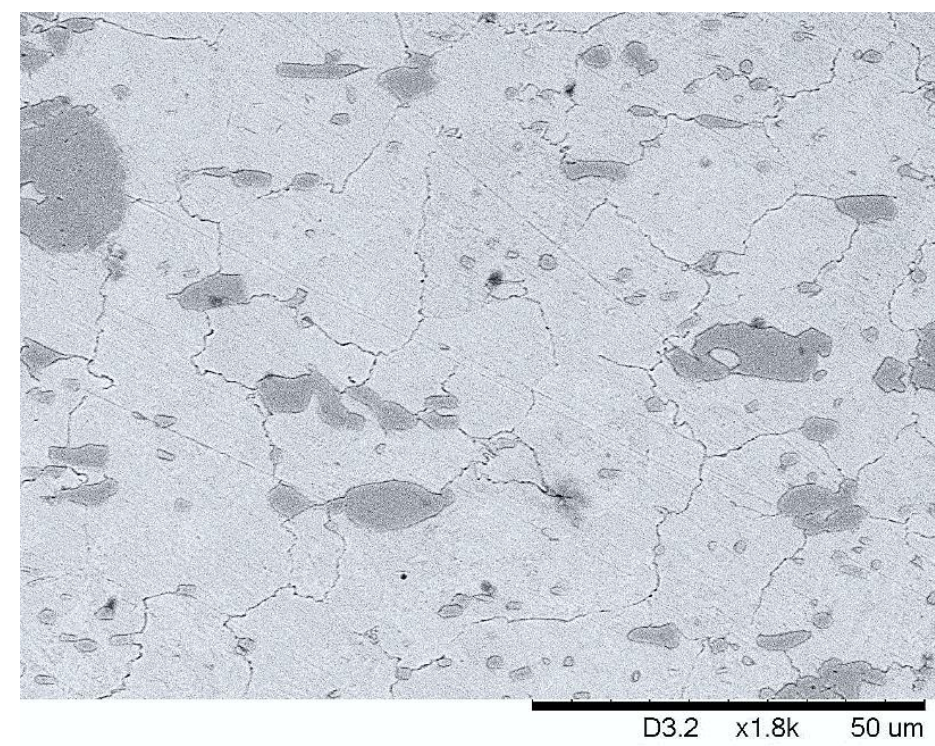

Figure 13. Microstructure of the heat affected zone.

$\mathrm{XRD}$ analysis was performed on the as-received and the thixo-joint samples to identify the phase evolution and the types of carbide formed after direct partial re-melting. The XRD spectrum patterns for the as-received D2 tool steel, thixo-joint without load and thixo-joint with $2.5 \mathrm{~N}$ load are presented in Figure 14(a), (b) and (c), respectively. The analysis of the diffraction patterns of as-received material found peaks corresponding to mainly the ferrite phase and iron-chromium carbide $\mathrm{M}_{7} \mathrm{C}_{3}$. The XRD pattern of the thixojoints after the application of the DPRM reflects the main two phases: austenite and $\mathrm{M}_{7} \mathrm{C}_{3}$ in the matrix. The presence of austenite is primarily connected with the increased content of $\mathrm{Cr}$ and $\mathrm{C}$ in the solid solution that stabilising the austenite [16]. Higher contents of these elements have a significant effect on the martensite temperature, and consequently, the transformation of austenite to martensite is difficult. Also, when relatively fast cooling from the solidus-liquidus range is applied, there is relatively better stability for the austenitic phase at room temperature [16].

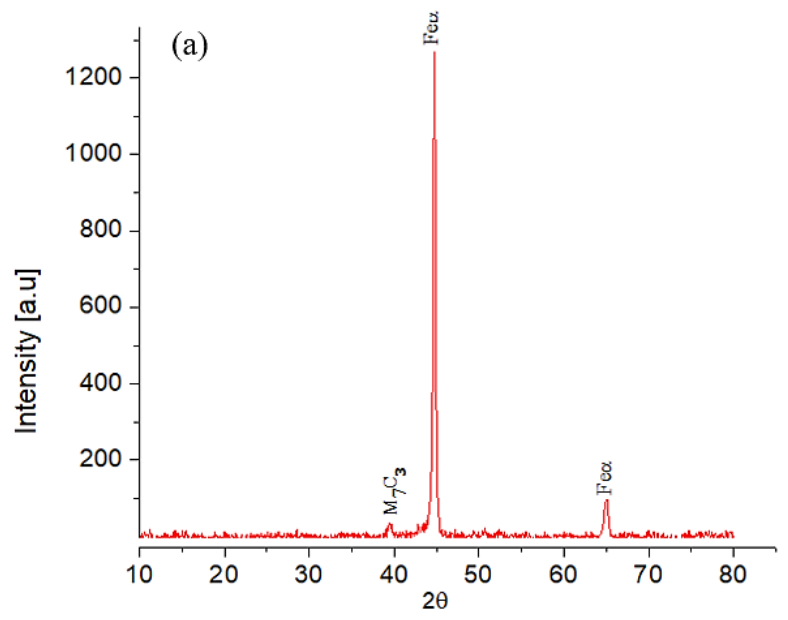



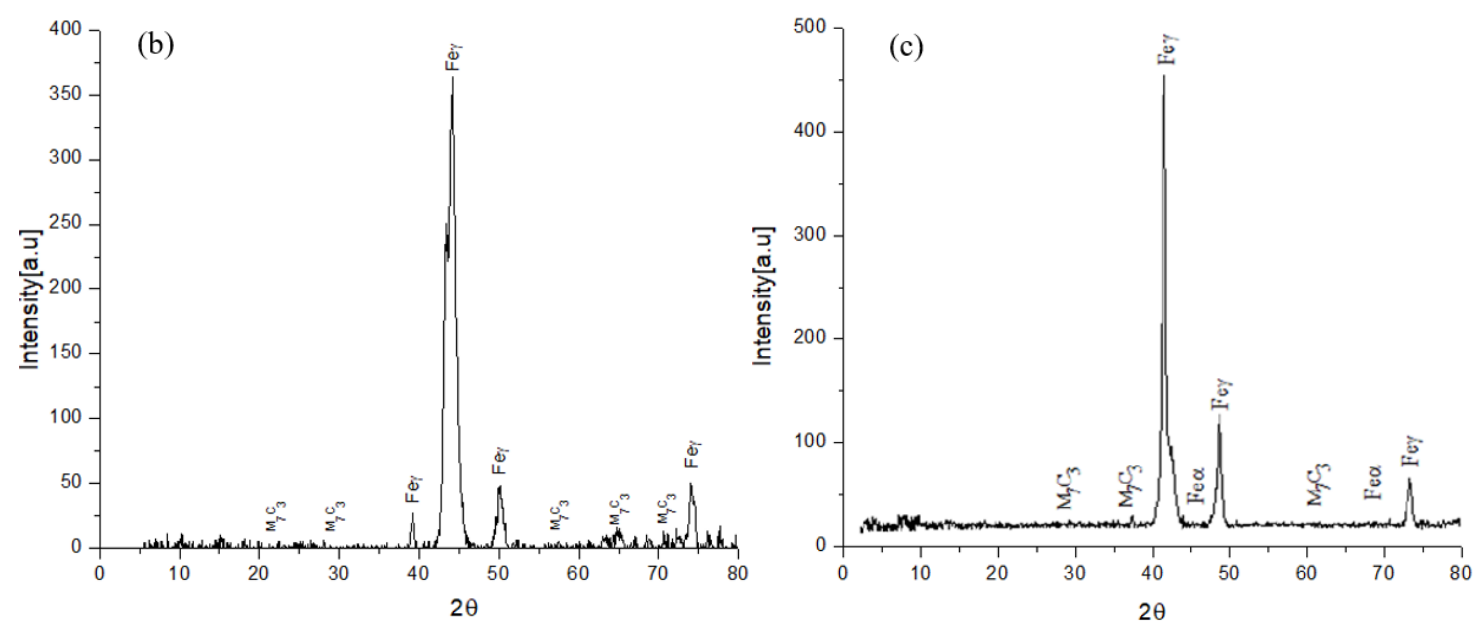

Figure 14. XRD analysis of (a) the as-received material, (b) thixo-joint without load, and (c) thixo-joint with $2.5 \mathrm{~N}$ load.

\section{CONCLUSION}

In this study, AISI D2 tool steel was butt joined using a direct partial re-melting method. The samples were partially melted by using an induction heating to prepare for a semisolid joining process. The conclusions are as follows:

1. The microstructure of the thixo-joint sample with $2.5 \mathrm{~N}$ load shows diffusion of grains boundaries due to the load applied at $1300^{\circ} \mathrm{C}$ during the thixotropic condition during the joining process. The microstructure at the joint area is mainly austenite with carbide network along the grain boundaries.

2. The load applied during the thixo-joining process improves the mechanical strength of the joint. The thixo-joint sample with $2.5 \mathrm{~N}$ compression load shows higher maximum strength compared to that of without load and is on a par with that of the as-received material.

3. The average hardness value within the thixo-joint area for the samples with and without load was increased to around $400 \mathrm{HV}$ due to the phase change of ferrite to the metastable austenite while precipitated eutectic carbides fill the remaining interparticle gaps at the grain boundaries.

\section{ACKNOWLEDGEMENTS}

The authors would like to thank the Universiti Kebangsaan Malaysia, Bangi for laboratory facilities and this work was supported in part by a grant from AP-2015-016. 


\section{REFERENCES}

[1] Candel JJ, Amigo V, Ramos JA, Busquets D. Problems in laser repair cladding a surface AISI D2 heat-treated tool steel. Welding International 2013; 27(1): 10-17.

[2] Omar MZ, Alfan A, Syarif J, and Atkinson HV. Microstructural investigations of XW-42 and M2 tool steels in semi-solid zones via direct partial re-melting route. Journal of Materials Science 2011; 46(24): 7696-7705.

[3] Mohammed MN, Omar MZ, Syarif J, and Salleh MS. Morphological Evolution during Partial Re-Melting of AISI D2 Cold-Work Tool Steel. Sains Malaysiana 2014; 43(8): 1213-1219.

[4] Mohammed MN, Omar MZ, Syarif J, Sajuri Z, Salleh MS and Alhawari KS. Investigations on Thixojoining Process of Steel Components. Journal of Mechanical Engineering and Sciences 2013; (5): 639-645.

[5] Kopp R, Kallweit J, Möller T, Seidl I. Forming and joining of commercial steel grades in the semi-solid state. Journal of Materials Processing Technology 2002; 130-131.

[6] Liu HW, Guo C. Technological parameters of stainless steel-aluminum alloy semisolid joining clad. Journal of Shanghai University. 2007; 510.

[7] Mohammed MN, Omar MZ, Salah Al-Zubaidi, Alhawari KS and Abdelgnei MA. Microstructure and mechanical properties of Thixowelded AISI D2 Tool Steel. Metals 2018; 8(5):316.

[8] Mohammed MN, Omar MZ, Salleh MS, Zailani MA, Alhawari KS. Joining two metals via partial remelting method. Journal of Asian Scientific Research 2012; 2(11): 724-730

[9] Kalaki A, Ketabchi M, Abbasi M. Thixo-joining of D2 and M2 tool steels: analysis of microstructure and mechanical properties. International Journal of Materials Research 2014; 105(8): 764-769.

[10] Kalaki A, Ketabchi M, and Zangeneh Sh. Fracture Surface Analysis in thixojoined tool steels. ISRN Materials Science 2014; Article ID 489487. http://dx.doi.org/10.1155/2014/489487

[11] Liu HW, Guo C, Cheng Y, Liu XF, and Shao GJ. Interfacial strength and structure of stainless steel-semi-solid aluminum alloy clad metal. Material Letters 2006; 60(2): 180-184.

[12] Burgos GR, Alexandrou AN, Entov V. Thixotropic rheology of semisolid metal suspensions. 2001. Journal of Materials Processing Technology 2001; 110(2): 164176.

[13] Roberts GA, Hamaker JC and Johnson JR. Tool steels, 2nd Ed. American Society for Metals, Metals Park, 1971.

[14] Alvani SMJ, Aashuri H, Kokabi A, and Beygi R. Semisolid joining of aluminum A356 alloy by partial remelting and mechanical stirring. Transactions of Nonferrous Metals Society of China (English Ed) 2010; 20(9): 1792-1798.

[15] Muro P, Gimenez S, Ituriza I. Sintering behaviour and fracture toughness characterization of D2 matrix tool steel comparison with wrough and PM D2. Scripta Materialia 2002; 46(5): 369-373.

[16] Aisman D, Jirkova H, Kucerova L, Masek B. Metastable structure of austenite base obtained by rapid solidification in a semi-solid state. Journal of Alloys and Compounds 2011; 509(1):312-315. 